\title{
Greatest Dimension Tumor
}

National Cancer Institute

\section{Source}

National Cancer Institute. Greatest Dimension Tumor. NCI Thesaurus. Code C157135.

A measurement of the widest portion of a tumor. 